\title{
On the osteology and phylogenetic affinities of the Pseudasturidae - Lower Eocene stem-group representatives of parrots (Aves, Psittaciformes)
}

\author{
GERALD MAYR \\ Forschungsinstitut Senckenberg, Sektion Ornithologie, Senckenberganlage 25, D-60325 Frankfurt a.M., Germany
}

\begin{abstract}
The osteology of the early Eocene (about 50 mya) avian taxon Pseudasturidae Mayr, 1998 is revised and its phylogenetic affinities are analysed. Members of the Pseudasturidae are known from abundant and excellently preserved skeletal material, both complete skeletons on slabs as well as isolated, three-dimensional bones. Although this taxon is thus among the best represented of all small early Tertiary birds, its systematic affinities were unknown so far. Derived osteological characters which are visible in newly recognized specimens from the Lower Eocene London Clay of England most convincingly support classification of the Pseudasturidae into the Psittaciformes (parrots). Both, in overall morphology and in terms of derived characters, the tarsometatarsus of the Pseudasturidae closely resembles that of the Eocene Quercypsittidae, which were assigned to the Psittaciformes by Mourer-Chauviré (1992). The Pseudasturidae are considered to be stem-group representatives of the Psittaciformes and the sister taxon of all other known psittaciform birds. The Eocene taxon lacks the specialized bill morphology of crown-group Psittaciformes of the Psittacidae. Several other osteological differences between the Pseudasturidae and the Psittacidae probably are also functionally correlated with the specialized feeding technique of the latter. (c) 2002 The Linnean Society of London, Zoological Journal of the Linnean Society, 2002, 136, 715-729.
\end{abstract}

ADDITIONAL KEYWORDS: Eocene - fossil birds - phylogeny - Pseudasturidae - stem-group Psittaciformes

\section{INTRODUCTION}

Today, most of the small perching birds belong to the Passeriformes (songbirds), which comprises more than half of the extant avian species. However, at least in the Northern Hemisphere, fossil passeriform birds are unknown before the end of the Oligocene, about million years ago (Mourer-Chauviré et al., 1989). Although meanwhile many well preserved small Eocene birds were discovered, all belong to non-passeriform taxa (e.g. Mlíkovský , 1996; Mourer-Chauviré, 1996; Mayr, 2000a). It is thus likely that by the early Tertiary, many ecological niches of small arboreal perching birds were occupied by representatives of other avian groups. Most perching birds are characterized by a specialized foot morphology, which enables them to embrace their perches. Within songbirds, this function is fulfilled by the greatly elongated hindtoe but in several other avian taxa with a relatively small hindtoe, the long fourth toe is either completely retroverted (zygodactyl foot) or can be spread

E-mail: gmayr@sng.uni-frankfurt.de laterally (semizygodactyl foot). Among extant birds, zygodactyl feet occur in all Psittaciformes (parrots), Cuculiformes (cuckoos) and in the Piciformes, which include the Galbulae (puffbirds, Bucconidae and jacamars, Galbulidae) and the Pici (barbets, toucans, woodpeckers and allies). Semizygodactyl and facultively zygodactyl feet are found in the Musophagidae (turacos), Coliiformes (mousebirds), Strigiformes (owls), and in the Madagascan Leptosomidae (cuckoo-rollers).

Only a few decades ago, very few zygodactyl birds were known from early Tertiary deposits. Feduccia \& Martin (1976) included all of the then known Eocene taxa in the Primobucconidae, which they considered to be closely related to extant Bucconidae (puffbirds). Houde \& Olson (1989), however, showed this taxon to be an entirely polyphyletic assemblage, and among the taxa that were incorrectly classified into the Primobucconidae is 'Primobucco' olsoni Feduccia \& Martin (1976), which is known from an almost complete, articulated skeleton from the Lower Eocene Green River Formation (USA). Although Houde \& Olson (1989) confirmed the assignment of 'Primobucco' olsoni to the Galbulae, they noted that it does not 
belong to the genus Primobucco, which lacks zygodactyl feet.

Birds that are closely related to 'Primobucco' olsoni are also represented in the Middle Eocene (about 49 mya) deposits of Messel, Germany (Fig. 1; Mayr, 1998a). At present, two species of this group were described from the locality, Pseudastur macrocephalus Mayr (1998a) and Serudaptus pohli Mayr (2000b), which are both known from complete articulated skeletons. Together with 'Primobucco' olsoni, Mayr (1998a, $2000 \mathrm{~b}$ ) assigned these birds to a new taxon, the Pseudasturidae, which he considered to be of uncertain phylogenetic affinities. Mayr (1998a: text-fig. 12) and Mayr \& Daniels (1998: pl. 5, fig. 17) further figured isolated bones of a pseudasturid bird from Lower Eocene London Clay deposits of Walton-on-the-Naze (Essex, England), which they tentatively referred to 'Primobucco' olsoni. However, associated remains of an individual of the very same species, also from
Walton-on-the-Naze, were recently described by Dyke $\&$ Cooper (2000) as a new genus and species, Pulchrapollia gracilis, and classified into the Psittaciformes (parrots). The authors did not recognize specific identity with the above-mentioned specimen and explicitly distinguished $P$. gracilis from the Pseudasturidae - all of the listed differences refer, however, to a misidentified coracoid (see Mayr, 2001; the coracoid of the Pseudasturidae is preserved in the complete articulated skeletons from Messel, as well as in the London Clay specimen figured by Mayr, 1998a). 'Primobucco' olsoni Feduccia \& Martin (1976) and Pulchrapollia gracilis Dyke \& Cooper (2000) appear to be extremely similar and might well be shown to be conspecific by direct comparison of the respective type specimens, in which case the species has to be referred to as Pulchrapollia olsoni (Feduccia \& Martin, 1976).

Dyke (2001a) described additional specimens of the Pseudasturidae from the London Clay and followed
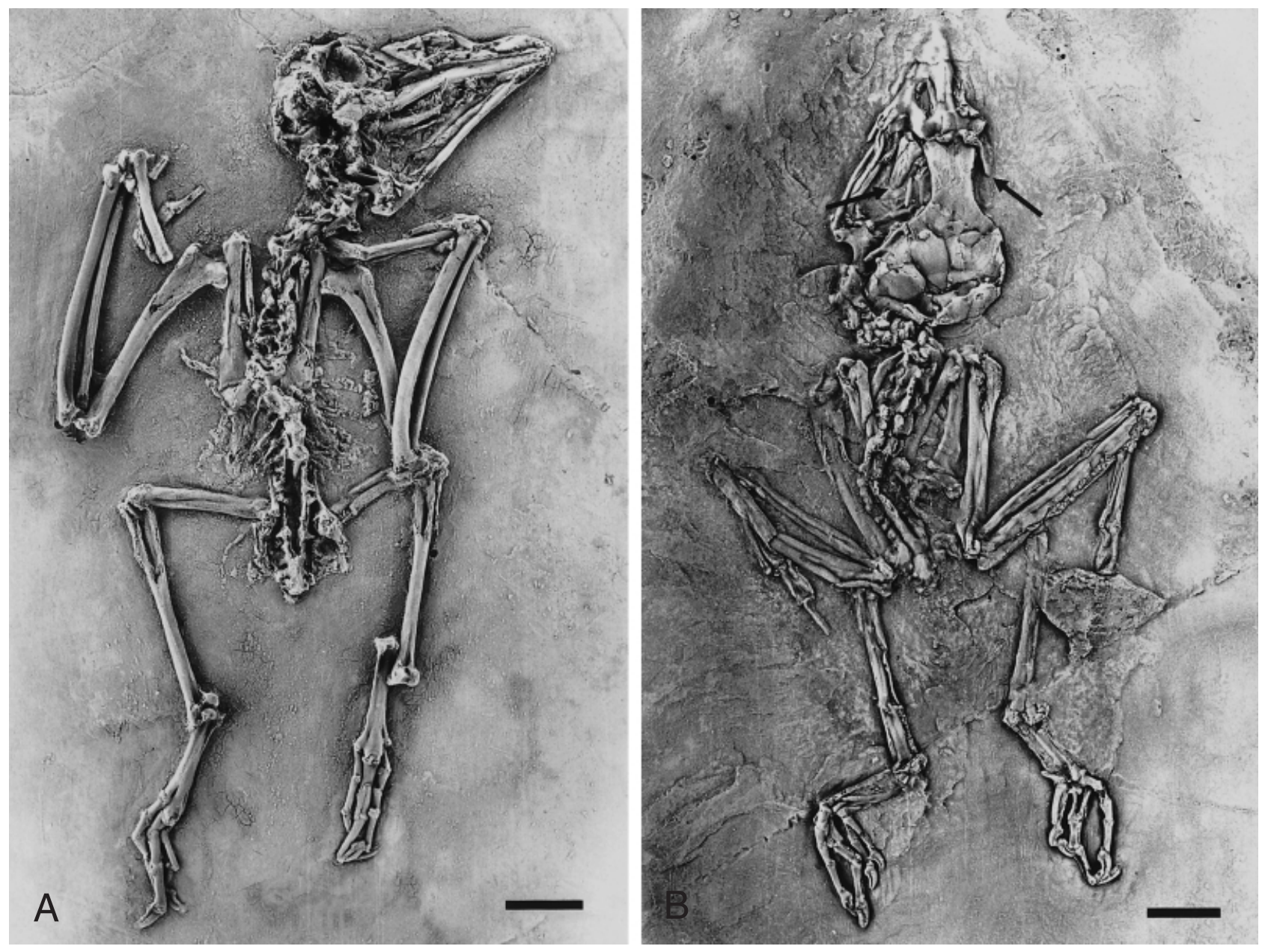

Figure 1. Articulated skeleton of Pseudastur macrocephalus Mayr (1998a) from the Middle Eocene of Messel, Germany (from Mayr, 1998a). (A) specimen WDC-C-MG 94; (B) specimen SMNK.PAL.2373a, the arrows indicate the large processus supraorbitales. Scale bars equal $10 \mathrm{~mm}$. 
Mayr (1998a) in considering the systematic position of this taxon to be uncertain. These remains were not compared with Pulchrapollia gracilis, because Dyke \& Cooper (2000) did not recognize the latter species as a member of the Pseudasturidae. My own survey of the London Clay material in the BMNH revealed further previously unrecognized specimens of the Pseudasturidae, among which is a proximal end of a left humerus that was made the paratype of the putative pratincole Precursor parvus by Harrison \& Walker (1977: 25).

The Pseudasturidae are known from comparatively abundant and excellently preserved skeletal material, both complete skeletons on slabs as well as isolated, three-dimensional bones, and are thus among the best represented of all early Tertiary birds. The newly recognized London Clay specimens show many previously unknown osteological details, which allow a much better understanding of the osteology of these birds. Unfortunately, however, their description by Dyke \& Cooper (2000) and Dyke (2001a) contains several mistakes and inaccuracies, and some of the characters used in the phylogenetic analysis of Dyke \& Cooper (2000) were incorrectly coded (Mayr, 2001). The aim of the present study is to revise the osteology of the London Clay Pseudasturidae and to evaluate the systematic affinities of this taxon.

\section{MATERIALS AND METHODS}

The fossil specimens are deposited in the Natural History Museum, London (BMNH), the Staatliches Museum für Naturkunde, Karlsruhe, Germany (SMNK) and in the Wyoming Dinosaur Center, Thermopolis, USA (WDC). Comparisons were made with all other, extant and fossil, zygodactyl birds and with a wide range of other extant avian taxa (based on skeletal material in the collection of the Forschungsinstitut Senckenberg). If not indicated otherwise, the osteological nomenclature follows Baumel \& Witmer (1993) and Vanden Berge \& Zweers (1993).

\section{SYSTEMATIC PALAEONTOLOGY}

\section{PSITTACIFORMES WAGLER, 1830}

\section{PSEUdASTURIDAE MAYR, 1998}

\section{MONOPHYLY}

The Pseudasturidae exhibit a highly characteristic osteology and are clearly distinguished from all other avian taxa. All pseudasturid taxa known so far further exhibit a very similar morphology. However, owing to the different kind of preservation of the respective specimens (articulated skeletons in Messel and the Green River Formation vs. isolated bones in the
London Clay deposits), not all of the following presumably autapomorphic features are visible in all taxa of the Pseudasturidae: (1) skull with large, caudally projecting processus supraorbitales (visible in the Messel specimens of Pseudastur macrocephalus); (2) sternum with strongly protruding apex carinae (visible in the holotypes of 'Primobucco' olsoni and Serudaptus pohli); (3) proximal end of humerus without foramen pneumaticum at bottom of fossa pneumotricipitalis (visible in the holotype of Pulchrapollia gracilis); (4) distal end of ulna with marked depressio radialis; (5) fossa poplitea at distal end of femur marked and bordered by sharp and pronounced crista supracondylaris medialis (visible in the holotype of Pulchrapollia gracilis); (6) medial foramen vasculare proximale much larger than lateral for. vasc. prox. (visible in the holotype of Pulchrapollia gracilis and the conspecific specimen figured by Mayr \& Daniels, 1998: fig. 17i); (7) second toe very thin and trochlea metatarsi II of tarsometatarsus very small. Other putatively derived characters which were listed by Mayr (1998a) in the diagnosis of the Pseudasturidae are also shared with the Psittacidae.

\section{EMENDED DESCRIPTION OF THE LONDON CLAY PSEUDASTURIDAE}

\section{Skull}

In the holotype of Pulchrapollia gracilis (BMNH A 6207) a praemaxilla and fragments of the mandible are preserved (Fig. 2), although for some reasons the presence of these bones was not mentioned by Dyke \& Cooper (2000). Unfortunately, comparison of the praemaxilla with that of Pseudastur macrocephalus and 'Primobucco' olsoni is difficult, because the latter species are preserved as more less flattened skeletons on slabs and their beaks thus probably appear wider than they actually were. The praemaxilla of $P$. gracilis is fairly narrow, the preserved part of the cristae tomiales is straight, and the culmen hardly curved. The beak itself apparently was dorsoventrally deep, as is that of Pseudastur macrocephalus.

An incomplete quadratum is preserved in the holotype of Pulchrapollia gracilis (Fig. 3A), which lacks the processus orbitalis and the processus oticus (erroneously, Dyke \& Cooper, 2000 described the latter as 'short and stocky'). The preserved portion of the quadratum shows a rather generalized morphology similar, for example, to the corresponding part of the quadratum of the extant Crested Coua, Coua cristata (Cuculidae). It does not show any of the highly apomorphic features of the quadrate of extant Psittacidae (e.g. condylus lateralis greatly reduced, condylus medialis and condylus pterygoideus fused; Fig. 3B), which is in concordance with the completely different beak morphology of Pseudasturidae and Psittacidae. 

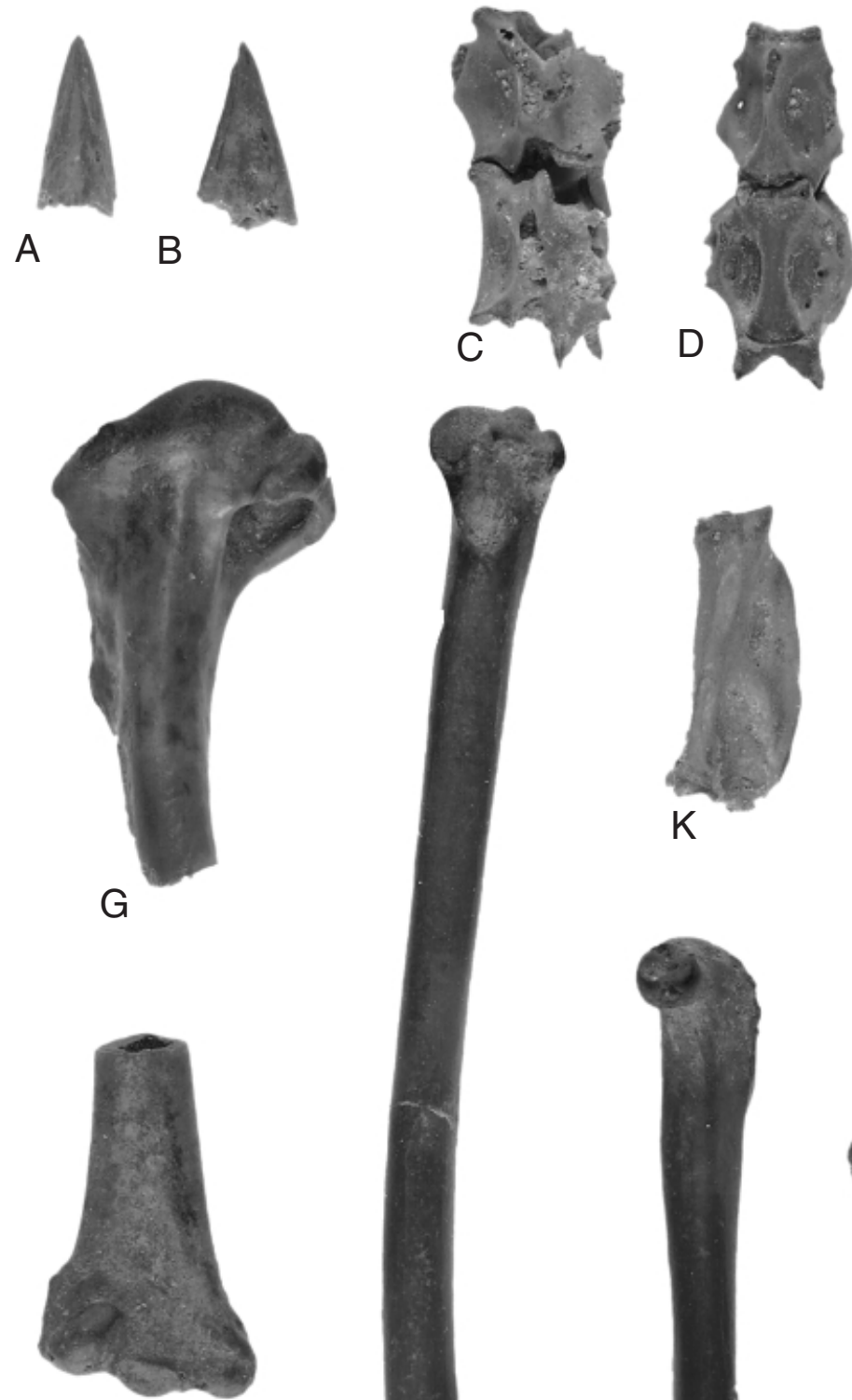

$\mathrm{H}$
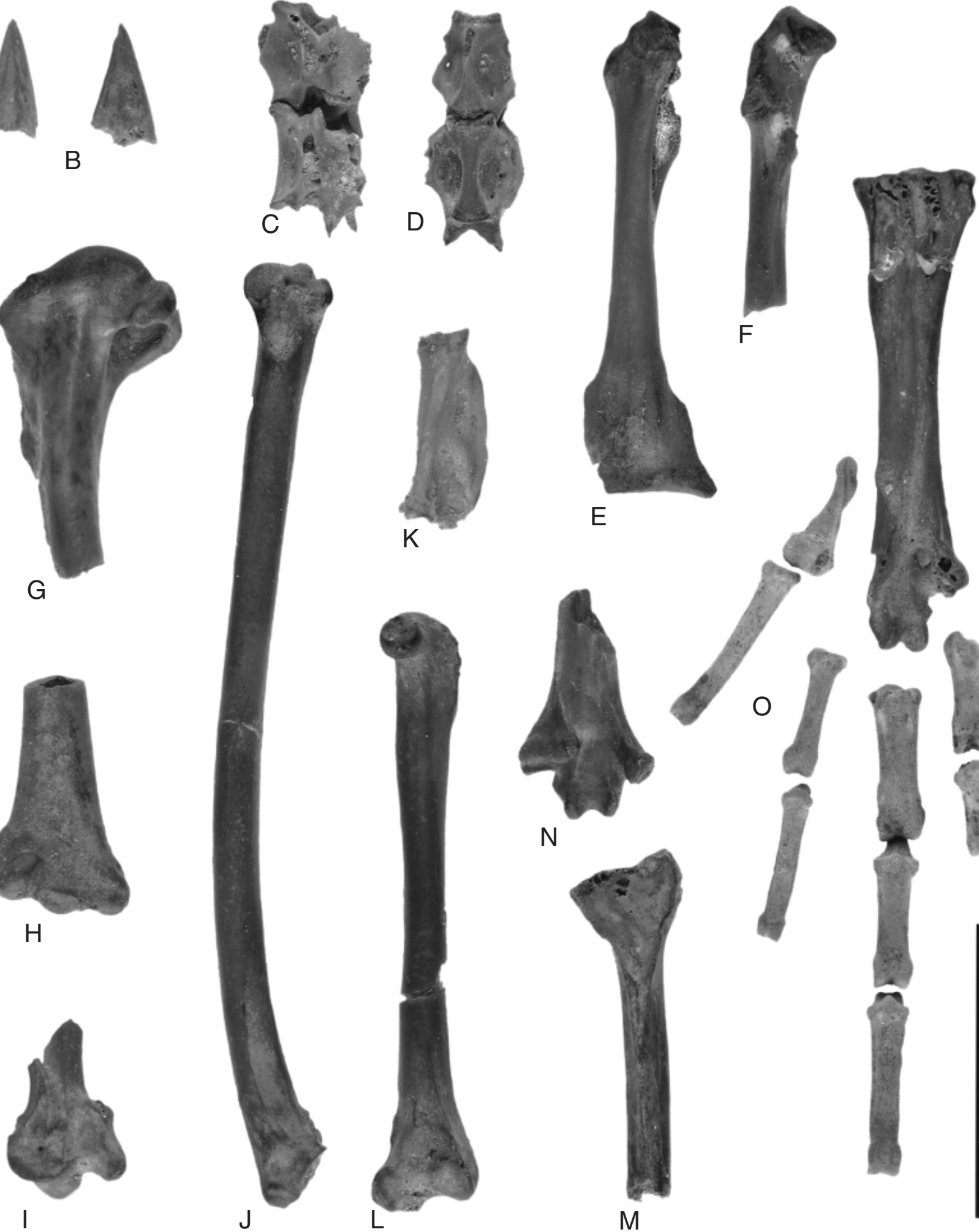
Figure 2. Selected skeletal elements of the London Clay Pseudasturidae. Pulchrapollia gracilis (holotype, BMNH A 6207), praemaxilla in (A) dorsal (B) left lateral view; Pulchrapollia gracilis (holotype, BMNH A 6207), two adjacent thoracic vertebrae in (C) left lateral and (D) ventral view; Pseudasturidae indet. (BMNH A 6218) from Walton-on-the-Naze, Essex (E) right coracoid in ventral view (F) left coracoid in dorsal view; (G) Pseudasturidae indet. (BMNH A 3553, paratype of Precursor parvus Harrison \& Walker, 1977), proximal end of left humerus in caudal view, from Warden Point, Sheppey, Kent; (H) Pseudasturidae indet. (BMNH A 6155), distal end of right humerus in cranial view, from Warden Point, Sheppey, Kent; (I) Pulchrapollia gracilis (holotype, BMNH A 6207), proximal end of right carpometacarpus in ventral view; (J) Pulchrapollia gracilis (holotype, BMNH A 6207), complete right ulna in ventral view; (K) Pulchrapollia gracilis (holotype, BMNH A 6207), left phalanx proximalis digiti majoris in dorsal view; (L) Pulchrapollia gracilis (holotype, BMNH A 6207), left femur (note that the specimen is broken and that the two halves are incorrectly stuck together); (M) Pulchrapollia gracilis (holotype, BMNH A 6207), proximal end of left tibiotarsus in medial view; (N) cf. Pseudastur macrocephalus (BMNH A 6184), complete distal end of left tarsometatarsus in plantar view, from Warden Point, Sheppey, Kent; (O) Pulchrapollia gracilis (holotype, BMNH A 6207), right tarsometatarsus in plantar view with associated pedal phalanges and os metatarsale I. Scale bar equals $10 \mathrm{~mm}$.

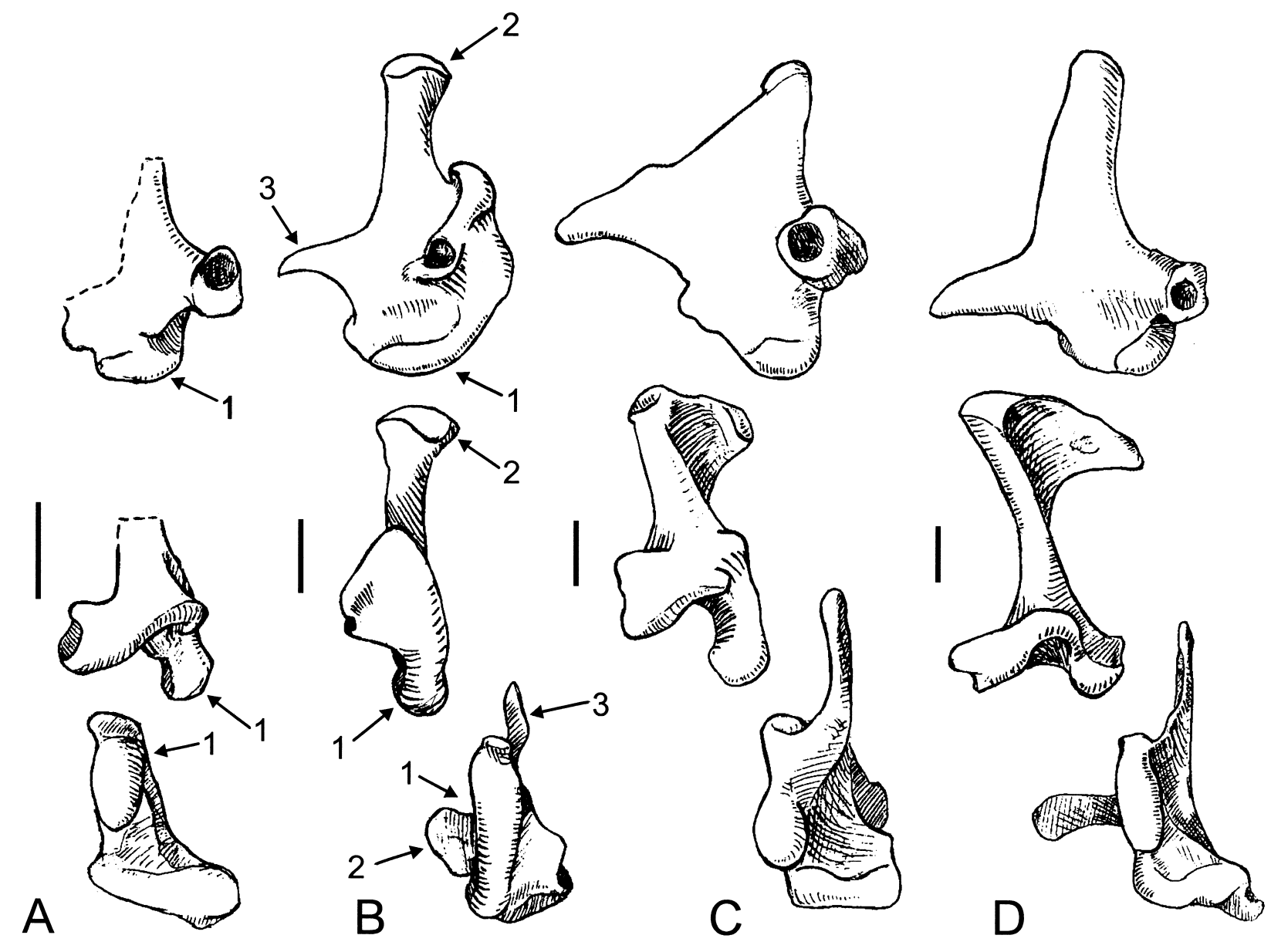

Figure 3. Left quadratum in comparison (upper row: lateral view, middle row: caudal view, lower row: ventral view). (A) Pulchrapollia gracilis (Pseudasturidae, BMNH A 6207); (B) Myiopsitta monachus (Psittacidae); (C) Monasa nigrifrons (Bucconidae); (D) Glaucidium passerinum (Strigiformes). The numerals indicate: 1 - condylus medialis; 2 - processus oticus; 3 - processus orbitalis. Note, that in P. gracilis both the processus orbitalis and the processus oticus are broken. Scale bars equal $2 \mathrm{~mm}$. 
The condylus medialis is not greatly enlarged as in extant Galbulae.

\section{Vertebrae}

In the type specimen of Pulchrapollia gracilis two adjacent thoracic vertebrae are preserved (Fig. 2), which also were not described by Dyke \& Cooper (2000). Both closely resemble the corresponding thoracic vertebrae of extant Psittacidae in that the corpus vertebrae is greatly compressed mediolaterally. Both vertebrae further bear a marked concavity on the lateral surface of the corpus vertebrae, which was also noted by Mayr (1998a) for Pseudastur macrocephalus. The more cranial of these two vertebrae exhibits a processus ventralis. Fragments of two other vertebrae are preserved but do not allow meaningful comparisons. In the Galbulae and Cuculidae, as in most other birds, the cranial thoracic vertebrae are not mediolaterally compressed.

\section{Coracoid}

The coracoid of the London Clay Pseudasturidae is preserved in specimen BMNH A 6218 (Pseudasturidae gen. et sp. indet.; Fig. 4A). In overall morphology, this bone is most similar to the coracoid of owls (Fig. 4B). It differs from the corresponding element of all other zygodactyl or semizygodactyl birds except the Leptosomidae and Strigidae in the presence of a foramen nervi supracoracoidei. It is less stout than the coracoid of extant Psittacidae and further differs in the smaller facies articularis clavicularis, which does not overhang the sulcus supracoracoideus, in the absence of pneumatic foramina under the facies articularis clavicularis, and in the proximo-distally wider processus procoracoideus. The angulus medialis is strongly protruding as in the specimens assigned to the Quercypsittidae by Mourer-Chauviré (1992). The facies articularis scapularis is not cup-like as in the Quercypsittidae. As in the coracoid of the Galbulae, there is a notch at the medial margin of the sternal extremity.

\section{Scapula}

The scapula is preserved in specimen BMNH A 6218 (Pseudasturidae gen. et sp. indet.). It differs from the corresponding bone of extant Psittacidae, Galbulae, Cuculidae and Strigiformes in the unusually short acromion.

\section{Humerus}

The humerus of the Pseudasturidae is long and slender and distinctly differs from the much stouter humerus of extant Psittacidae. Apart from the smaller crista deltopectoralis (which is similar in relative size to that of the Cuculidae), it most closely resembles the humerus of recent Galbulae, both in its proportions and in overall morphology. The proximal end of the bone is best preserved in specimen BMNH A 3553 (Pseudasturidae gen. et sp. indet., Fig. 2G), which was made the paratype of Precursor parvus by Harrison \& Walker (1977: 25). It is most distinctive in that it lacks pneumatic foramina on the bottom of the fossa pneumotricipitalis. Although these foramina are absent in several extant birds as, for example, rails (Rallidae), they are present in all extant zygodactyl birds (very
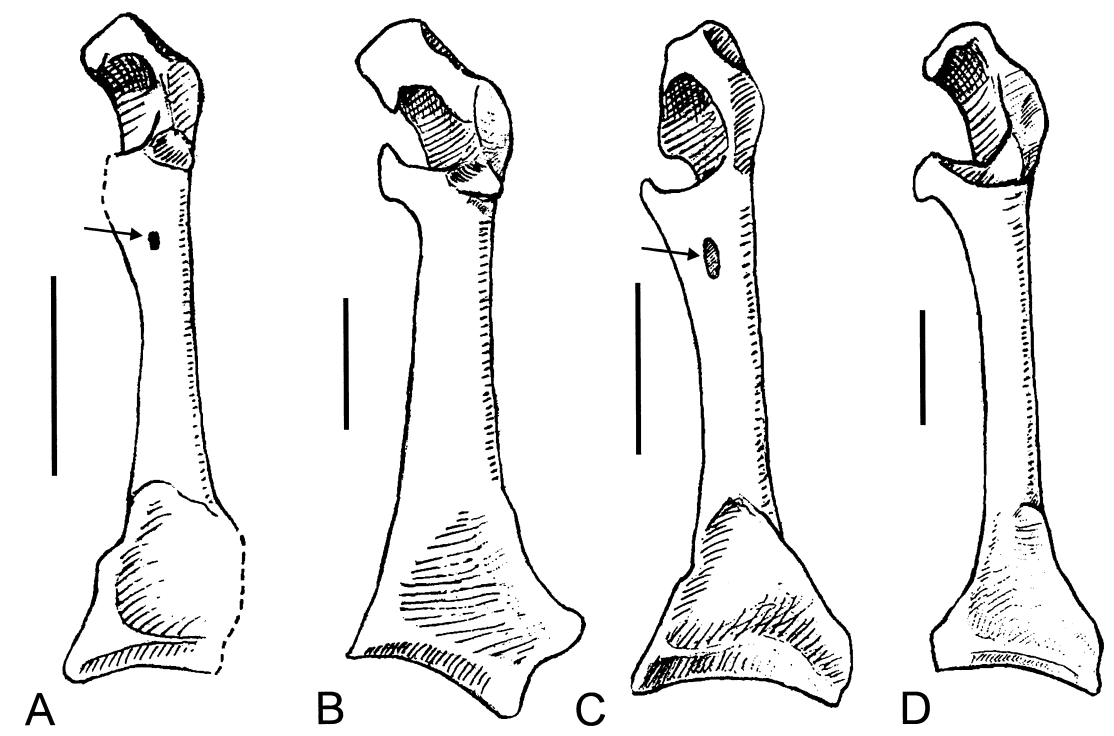

Figure 4. Right coracoid in comparison. (A) Pseudasturidae gen. et. sp. indet. (BMNH A 6218); (B) Myiopsitta monachus (Psittacidae); (C) Otus scops (Strigiformes); (D) Crotophaga major (Cuculidae). The arrows indicate the foramen nervi supracoracoidei. Scale bars equal $5 \mathrm{~mm}$. 


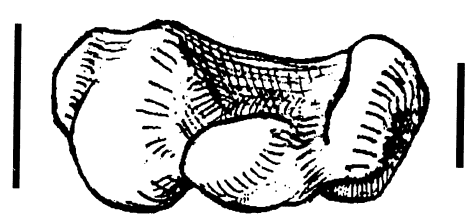

A
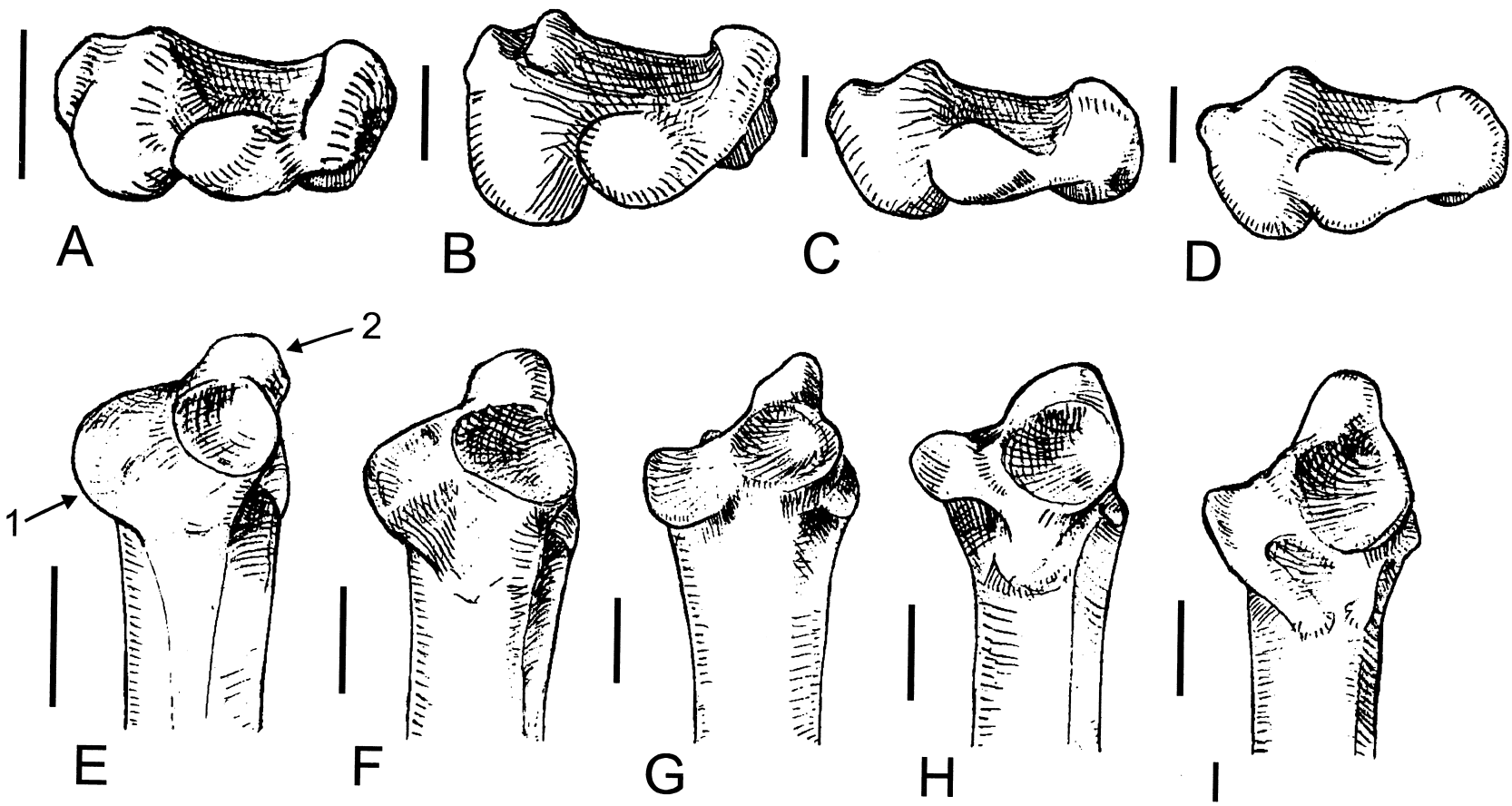

Figure 5. Distal end of left humerus (A-D) and proximal end of right ulna (E-I) in comparison. (I) Pulchrapollia gracilis (Pseudasturidae, BMNH A 6207); (B) Myiopsitta monachus (Psittacidae); (C) Monasa nigrifrons (Bucconidae); (D) Coua cristata (Cuculidae); (E) Pulchrapollia gracilis (Pseudasturidae, BMNH A 6207); (F) Otus scops (Strigiformes); (G) Myiopsitta monachus (Psittacidae); (H) Coua cristata (Cuculidae); (I) Monasa nigrifrons (Bucconidae). The numerals indicate: 1 processus cotylaris dorsalis; 2 - olecr anon Scale bars equal $2 \mathrm{~mm}$.

small, however, in some Psittacidae, as Eos histrio). The distal end of the humerus is preserved in the type of Pulchrapollia gracilis and in BMNH A 6155 (Pseudasturidae gen. et. sp. indet.) (Fig. 5A). It is characterized by a small condylus dorsalis, an elongate condylus ventralis which bears a depression along its cranial surface, and a distinct incisura intercondylaris. The fossa musculi brachialis is situated near the ventral margin of the bone. Both the sulcus scapulotricipitalis and the sulcus humerotricipitalis are shallow. The distal end of the humerus of the Psittacidae is craniocaudally much wider (Fig. 5B) and bears a shorter processus flexorius and a larger condylus dorsalis. Likewise, the distal end of the humerus of the Pseudasturidae is distinguished from that of the Cuculidae in that the processus flexorius is less medially protruding and the condylus ventralis is less globular.

\section{Ulna}

A complete right ulna is preserved in the holotype of Pulchrapollia gracilis and closely resembles the corresponding bone of some extant Strigiformes, e.g. Otus scops (Strigidae). As in the Galbulae, the processus cotylaris dorsalis at the proximal end of the ulna is very large and continuous with the incisura radialis
(Fig. 5A). The depressio radialis at the distal end of the ulna is marked, as in Pseudastur macrocephalus (see Mayr, 1998a). The ulna of Psittacidae and Cuculidae is much stouter, the processus cotylaris dorsalis much smaller.

\section{Carpometacarpus}

In the holotype of Pulchrapollia gracilis the proximal end of the right carpometacarpus is preserved. It is very similar to the carpometacarpus of the Quercypsittidae (Mourer-Chauviré, 1992: pl. 2), although the fovea carpalis cranialis is less marked. It differs from the carpometacarpus of extant Psittacidae in that the processus pisiformis is not shifted cranially and lacks the distinct elevation caudal to it, and in the less protruding processus extensorius. In extant Galbulae, the processus extensorius is even more protruding than in the Psittacidae, the processus pisiformis situated farther cranially, and there is a distinct processus intermetacarpalis.

\section{Other elements of the wing}

The proximal phalanx digiti majoris is preserved in the holotype of Pulchrapollia gracilis. This element resembles the corresponding bone of extant Psittacidae but is narrower in craniocaudal direction and 
lacks a well developed processus internus indicis (terminology after Stegmann, 1963). The hooked proximal phalanx digiti majoris of the Galbulae exhibits a highly apomorphic morphology and differs strongly from that of the Pseudasturidae.

\section{Femur}

In overall morphology, the femur of Pulchrapollia gracilis resembles the corresponding bone of extant Psittacidae (e.g. Myiopsitta monachus). It is, however, distinguished by the shallower sulcus intercondylaris, the unusually small lateral rim of the trochlea fibularis, and by the marked fossa poplitea, which is bordered by a sharp and pronounced crista supracondylaris medialis. On the proximal end, the caput femoris is proximo-distally narrow, the fovea ligamenti capitis is distinct. Among other features, the femur of the Cuculidae differs in the more globular caput femoris and the more distinct sulcus intercondylaris.

\section{Tibiotarsus}

The proximal end of the left tibiotarsus is preserved in the holotype of Pulchrapollia gracilis. As in extant Psittacidae, the cristae cnemiales are hardly protruding. The facies gastrocnemialis is distinctly raised and there is a low ridge along the medial side of the bone, opposite to the crista fibularis. This ridge, which was not mentioned by Dyke \& Cooper (2000), is also present in the pseudasturid genus Serudaptus (see Mayr, 2000b) and most extant psittaciform taxa.

Also in the holotype of P. gracilis, the proximal end of the left fibula is preserved; this bone was erroneously considered to be the proximal end of the scapula by Dyke \& Cooper (2000: pl. 1, fig. 7).

\section{Tarsometatarsus}

Of all skeletal elements of the Pseudasturidae, the tarsometatarsus most closely resembles the corresponding bone of psittaciform birds, especially if comparisons are made with the Upper Eocene Quercypsittidae Mourer-Chauviré (1992). As seen in the holotype of Pulchrapollia gracilis, the bone is strongly compressed in dorso-plantar direction. The hypotarsus bears two furrows, presumably for the tendons of musculus flexor hallucis longus and $\mathrm{m}$. flexor digitorum longus (visible in the London Clay specimen figured by Mayr, 1998a: text-fig. 12). In extant Psittacidae the hypotarsal conformation shows considerable variability but the presence of two closed hypotarsal canals is probably the primitive condition. The hypotarsus of the Eocene psittaciform birds described by Mayr \& Daniels (1998) also exhibits two furrows or a furrow and a canal, respectively. The
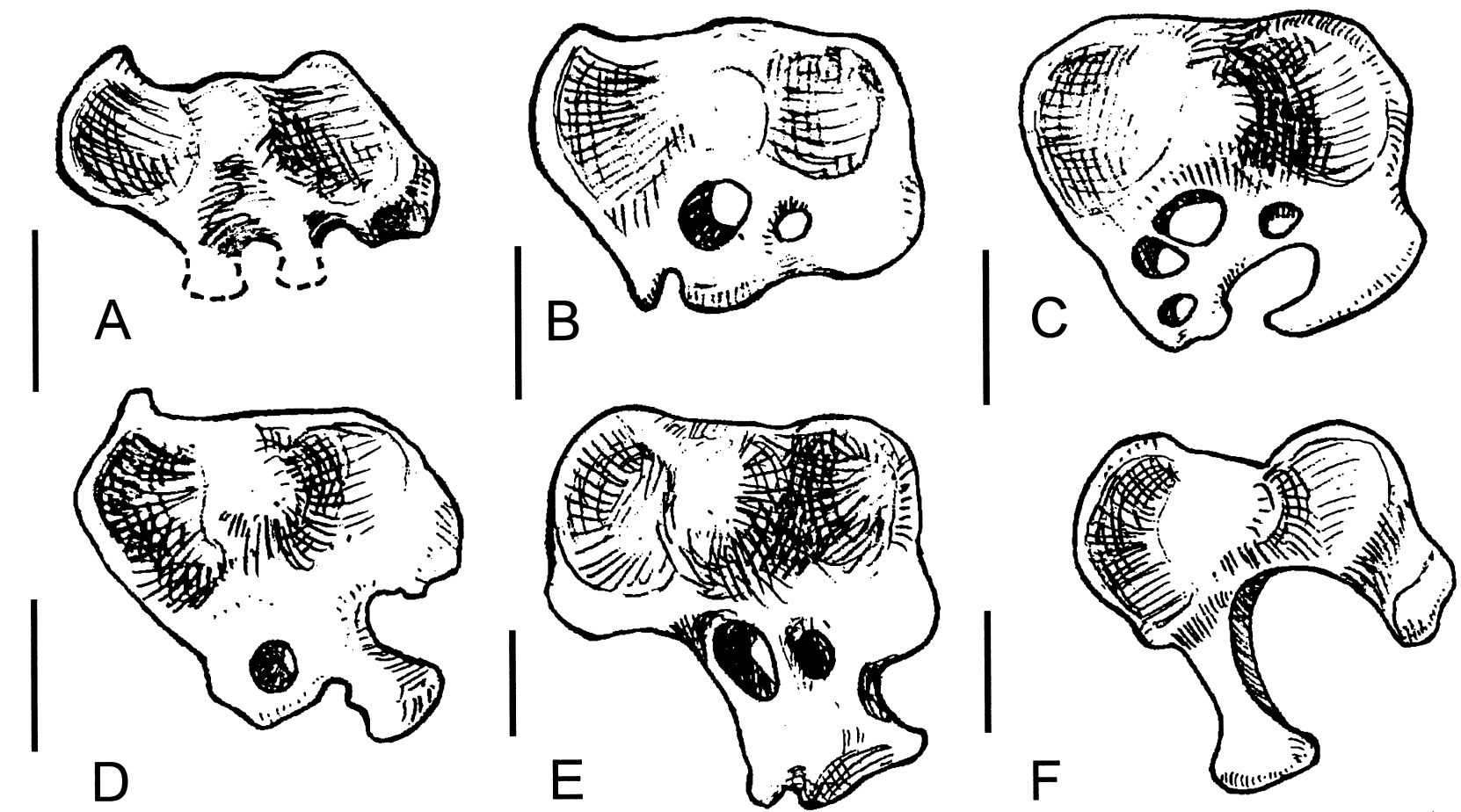

Figure 6. Proximal end of right tarsometatarsus in comparison. (A) Pulchrapollia gracilis (Pseudasturidae, BMNH A 6207), the dotted area has been reconstructed after the specimen figured by Mayr (1998a: text-fig. 12); (B) Nymphicus hollandicus (Psittacidae); (C) Cyanoramphus novaezelandiae (Psittacidae); (D) Monasa nigrifrons (Bucconidae); (E) Coua cristata (Cuculidae); (F) Otus scops (Strigiformes). Scale bars equal $2 \mathrm{~mm}$. 
hypotarsus of the Cuculidae is perforated by two canals, that of the Galbulidae bears a furrow and a canal, whereas the hypotarsus of the Strigiformes is completely different from that of the Pseudasturidae in that the crista lateralis is separated from the crista medialis by a wide sulcus (Fig. 6). In Pulchrapollia gracilis the medial foramen vasculare proximale is unusually large, whereas it is extremely reduced or completely absent in extant Psittacidae (owing to the preservation of the respective specimens, this feature is not clearly visible in the other species of the Pseudasturidae). The tarsometatarsus of the holotype of Pulchrapollia gracilis lacks most of the trochleae for the second and fourth toe, but with specimen BMNH A 6184 (cf. Pseudastur macrocephalus) a perfectly preserved distal end of a pseudasturid tarsometatarsus is available (Fig. 2). Contrary to extant Psittacidae but as in most Cuculidae (except, for example, Geococcyx), the trochlea metatarsi II is very small. As already noted by Dyke (2001a), it is almost cube-shaped, with the distal articular surface being flat. As in all Psittaciformes but contrary to other zygodactyl birds, the trochlea metatarsi III is very wide mediolaterally but narrow in dorsoplantar direction; its dorsal surface is not significantly raised above the dorsal surface of the shaft. The rims are symmetrical and widely separated by a marked furrow (the trochlea metatarsi III of the genus Pulchrapollia is somewhat narrower than that of Pseudastur, see Fig. 2). The trochlea metatarsi IV bears a well developed trochlea accessoria, the Sehnenhalter of Steinbacher (1935), which keeps the tendon of musculus flexor digitorum longus. Among extant birds, a similarly enlarged trochlea accessoria only occurs within the Psittacidae, Cuculidae, Galbulae and Pici (in the Psittacidae and Pici it is even much more enlarged). The trochlea metatarsi IV is continuous with the trochlea accessoria, whereas in extant Psittacidae and the Eocene taxa described by Mayr \& Daniels (1998), the trochlea accessoria is separated from the trochlea metatarsi IV by a furrow for the tendon of musculus flexor perforatus digiti IV (see Steinbacher, 1935: 271, who used the term 'musculus flexor perforans digiti IV' for this muscle), which is, however, poorly developed in the Quercypsittidae (Mourer-Chauviré, 1992). Contrary to extant Psittacidae but as in the Quercypsittidae, the plantar surface of the trochlea accessoria of the Pseudasturidae is not orientated parallel to the plantar surface of the tarsometatarsus. The articulation facet of the actual trochlea metatarsi IV is much smaller than in the Cuculidae and Galbulae. As in the Psittacidae but also contrary to Galbulae and Cuculidae, there is a furrow on the distal end of the tarsometatarsus, between the dorsal side of the trochlea metatarsi IV and the incisura intertrochlearis lateralis (Fig. 7), which is here considered to be an autapomorphic feature of psittac- iform birds. A canalis interosseus distalis is absent, instead there is a distinct, dorsally open furrow for the tendon of musculus extensor brevis digiti IV, which is also visible in the Quercypsittidae (in extant Psittacidae, which according to Steinbacher, 1935: 271, lack the m. ext. brev. dig. IV, there is no such furrow). The foramen vasculare distale is large.

\section{Pedal phalanges}

Eight pedal phalanges and the os metatarsale I are preserved in the type specimen of Pulchrapollia gracilis (Fig. 2). As in Pseudastur macrocephalus, the third toe is very robust and the second toe unusually thin. The proximal phalanx of the first toe is slightly bowed. Contrary to extant Psittacidae, the os metatarsale I bears a long processus articularis tarsometatarsalis.

\section{DISCUSSION}

\section{PSITTACIFORM RELATIONSHIPS OF THE PSEUDASTURIDAE}

The Pseudasturidae share significant derived characters with only few extant taxa and their zygodactyl feet especially suggest comparisons with other zygodactyl birds. As outlined in the Introduction, the Eocene taxon indeed was either classified into the Galbulae (Feduccia \& Martin, 1976; Houde \& Olson, 1989; Feduccia, 1996;: 341) or, accidentally, however, into the Psittaciformes, as a sister taxon of the Psittacidae (Dyke \& Cooper, 2000). Mayr (1998a) further discussed a possible relationship to strigiform and falconiform birds.

Classification of the Pseudasturidae into the Galbulae cannot be convincingly supported with derived characters. The characters listed by Houde \& Olson (1989: 2031) in order to support assignment of 'Primobucco' olsoni to the Galbulae are either plesiomorphic or of uncertain polarity ('thoracic and caudolateral processes of sternum arising separately', 'carpometacarpus with metacarpals of roughly equal length and short distal symphysis', 'limb proportions similar to those of the Bucconidae', 'humerus slender and curved with a small pectoral crest and small condyles'), also found in other zygodactyl birds as the Psittacidae ('tarsometatarsus with a very broad third trochlea and conspicuously large lateral epicondyle', 'proximal phalanges of digit III extremely robust'), or incorrect ('presence of unique configuration of the sehnenhalter' - the trochlea accessoria, or Sehnenhalter, of the Pseudasturidae is only superficially similar to that of the Galbulae, see description above and Fig. 7; 'cranium with large postorbital process' - the processus postorbitalis of the Pseudasturidae is not as greatly enlarged as that of the Galbulae; 'posterior 

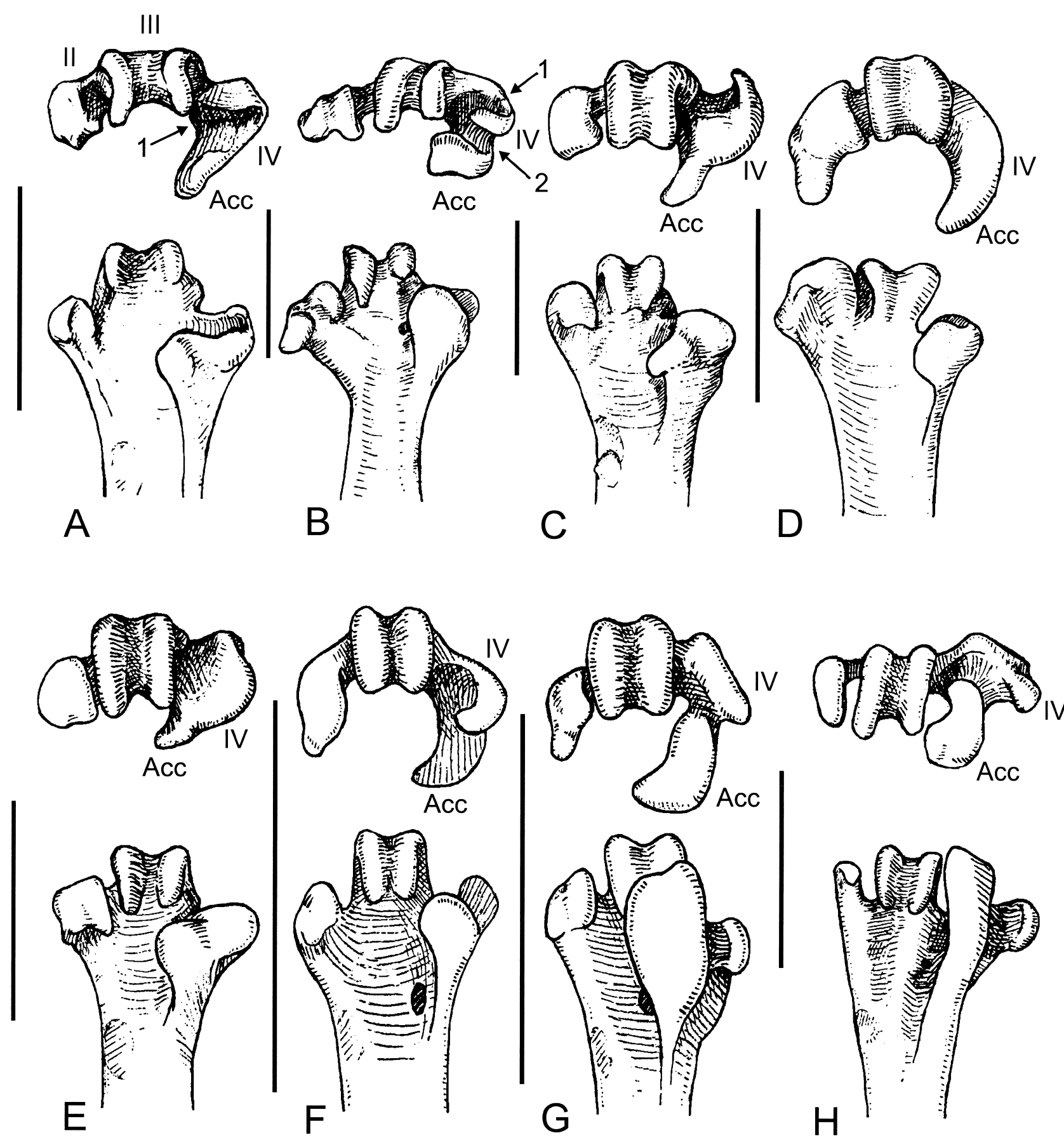

Figure 7. Distal end of left tarsometatarsus in comparison (upper row: distal view, lower row: plantar view). (A) cf. Pseudastur macrocephalus (Pseudasturidae, BMNH A 6184; Eocene) (B) Myiopsitta monachus (Psittacidae; recent); (C) Coua cristata (Cuculidae; recent); (D) Otus scops (Strigiformes; recent); (E) Monasa nigrifrons (Bucconidae; recent); (F) cf. Primozygodactylus sp. (Primoscenidae, Primoscenidae; Eocene), after Mayr (1998b); (G) Zygodactylus grivensis (Zygodactylidae, Piciformes; Miocene), after Mayr (1998b); (H) Lybius bidentatus (Capitonidae, Piciformes; recent). The trochleae metatarsorum II-IV (Roman numerals) and the trochlea accessoria (Acc) are indicated. Arabic numerals indicate: 1 tendineal furrow along medial side of basis of trochlea metatarsi IV; 2 - furrow for tendon of musculus flexor perforatus digiti IV. Scale bars equal $5 \mathrm{~mm}$. 
border of sternum deeply notched' - the incisions of the margo caudalis of the sternum of the Pseudasturidae are not as deeply notched as those of the Galbulae).

Pseudasturidae, falconiform and strigiform birds share very large, caudally projecting processus supraorbitales (Fig. 1) and owls further exhibit an at least semizygodactyl foot. Enlarged processus supraorbitales evolved, however, several times independently in birds (they are, for example, also present in many rails, Rallidae, and some kingfishers, Alcedinidae), and the Pseudasturidae do not share unique derived characters with raptorial birds. Contrary to earlier statements (Mayr, 1998a), I now consider it more likely that the presence of a foramen nervi supracoracoidei is plesiomorphic within neornithine birds. This foramen also occurs in the palaeognathous Lithornithidae (Houde, 1988) and evidently is secondarily reduced in several higher avian taxa, e.g. Anseriformes (Livezey, 1986), Charadriiformes (Björklund, 1994) or Accipitridae (Olson, 1987).

Monophyly of Pseudasturidae and Cuculidae also cannot be established with derived characters, and sister group relationship between Cuculidae and the semizygodactyl Musophagidae is supported by several analyses based on morphology or molecular data (e.g. Gadow, 1893; Stresemann, 1927,34; Cracraft, 1981; Hughes \& Baker, 1999; Hughes, 2000).

The two 'unambiguous synapomorphies' listed by Dyke \& Cooper (2000: 278) in order to support classification of Pulchrapollia into the Psittaciformes are also present in the Galbulae and Cuculidae (i.e. trochlea metatarsi III bearing a tubercle on lateral side, and trochlea metatarsi IV being completely retroverted). However, apart from the zygodactyl feet, the following derived characters indeed most convincingly support classification of the Pseudasturidae into the Psittaciformes (as used in this study, the term includes both the representatives of the extinct stemlineage and the members of the crown-group, i.e. the Psittacidae):

(1) Corpus of cranial thoracic vertebrae strongly mediolaterally compressed. This unquestionably derived feature is absent in the Cuculidae and Galbulae.

(2) Proximal end of tibiotarsus with ridge along medial side, opposite to crista fibularis. This ridge certainly is derived within neornithine birds but also occurs as a distinct crest in mousebirds and Pici, whereas it is absent in other zygodactyl birds including the Galbulae.

(3) Distal end of tibiotarsus with proximo-distally short, small condyles which are separated by a wide incisura intercondylaris, width across the condyles greater than height of condyles. In the Cuculidae, Pici, Galbulae, and most other birds, the width across the condyles is as much or less than the height of the condyles, which presumably is the primitive condition within neornithine birds.

(4) Trochlea metatarsi III much wider in mediolateral than in dorsoplantar direction, with a distinct groove between the rims; its dorsal surface not being significantly raised above the dorsal surface of the shaft. This character is not found in other zygodactyl birds and here is considered to be autapomorphic for the Psittaciformes. In most other avian taxa the trochlea metatarsi III is wider in dorsoplantar than in mediolateral direction, which certainly is the primitive condition.

(5) Furrow on distal end of tarsometatarsus, between dorsal side of trochlea metatarsi IV and incisura intertrochlearis lateralis (Fig. 7). This character is here considered to be an autapomorphic feature of psittaciform birds (the furrow is indistinct in a few members of the Psittacidae as, for example, Nestor notabilis and Amazona spp.).

The Pseudasturidae further agree with other psittaciform birds but differ from the Galbulae in the robust, dorsoventrally deep beak (visible in the Messel specimens, see Mayr, 1998a, 2000b). Many of the trenchant osteological differences between the Pseudasturidae and extant Psittacidae are probably due to the more plesiomorphic osteology of the former, and are relativized if the Pseudasturidae are compared with other Eocene stem-group Psittaciformes.

\section{Phylogeny Within the PsitTaciformes}

Until recently, psittaciform birds had a poor fossil record and most fossil taxa listed by Olson (1985) belong to the psittaciform crown-group, the Psittacidae (the Lower Eocene genus Palaeopsittacus was incorrectly referred to the Psittaciformes by Harrison, 1982; see Mayr \& Daniels, 1998). Meanwhile, however, several stem-group Psittaciformes were described, the earliest reliable records of which are from Lower Eocene deposits (a recently described fragmentary lower jaw from the Cretaceous of North America cannot be convincingly shown to be from a parrot, see Stidham, 1998; Dyke \& Mayr, 1999).

Members of stem-group Psittaciformes of the Quercypsittidae Mourer-Chauviré (1992) are known from isolated elements from the Upper Eocene of the Quercy, France (Mourer-Chauviré, 1992) and the Lower Eocene London Clay (Mayr \& Daniels, 1998). The Quercypsittidae are clearly distinguished from the Pseudasturidae by features of the coracoid (Mayr, 1998a: 201). Mayr \& Daniels (1998) described another distinctive group of early Eocene stem-group psittaciform birds from Messel and the London Clay. The species from Messel, Psittacopes lepidus Mayr \& Daniels (1998), is known from two articulated skele- 

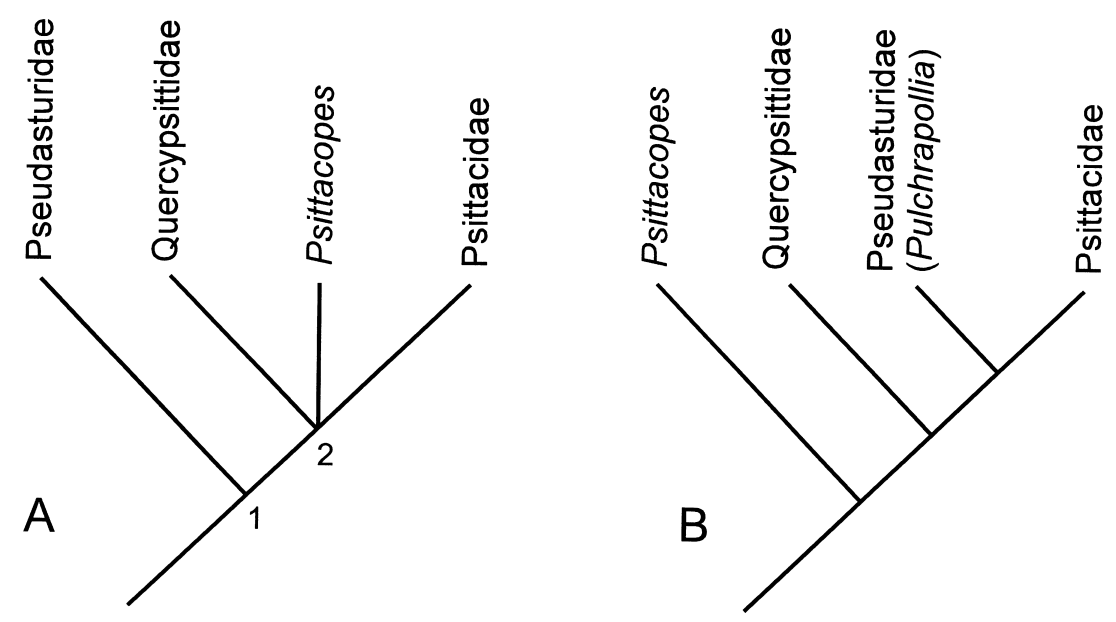

Figure 8. Phylogenetic relationships between the Pseudasturidae Mayr (1998a), the Eocene Quercypsittidae MourerChauviré (1992), the Eocene psittaciform taxon Psittacopes Mayr \& Daniels (1998) and the crown-group Psittacidae. (A) the phylogeny proposed in this study; (B) the result of a cladistic analysis by Dyke \& Cooper (2000). The nodes in (A) are supported by the following derived characters: Node 1: (1) corpus of cranial thoracic vertebrae strongly mediolaterally compressed; (2) proximal end of tibiotarsus with ridge along medial side, opposite to crista fibularis; (3) distal end of tibiotarsus with proximo-distally short condyles which are separated by a wide incisura intercondylaris; (4) trochlea metatarsi III much wider in mediolateral than in dorsoplantar direction, with a distinct groove between the rims, dorsal surface not significantly raised above dorsal surface of the shaft; (5) furrow on distal end of tarsometatarsus, between dorsal side of trochlea metatarsi IV and incisura intertrochlearis lateralis. Node 2: (1) furrow for tendon of musculus flexor perforatus digiti IV between trochlea accessoria and trochlea metatarsi III.

tons; the London Clay material is currently deposited in a private collection. These birds, which belong to a yet unnamed extinct higher-level taxon, closely resemble extant Psittacidae in most elements of the postcranial skeleton but also lack the highly apomorphic beak of extant parrots. The earliest record of members of the Psittacidae is from early Miocene deposits (Wetmore, 1926; Mlíkovský , 1998; Cheneval, 2000).

The Pseudasturidae are a third taxon of stem-group Psittaciformes and are here considered to be the sister taxon of all other known psittaciform birds (Fig. 8A). A derived feature which supports monophyly of the Quercypsittidae, the Eocene psittaciform birds described by Mayr \& Daniels (1998), and the Psittacidae, to the exclusion of the Pseudasturidae, is the presence of a furrow for the tendon of musculus flexor perforatus digiti IV between the trochlea accessoria and the trochlea metatarsi III (Fig. 9, this furrow is only weakly developed in the Quercypsittidae). The Pseudasturidae further differ from all other known psittaciform birds in the presence of a foramen nervi supracoracoidei at the coracoid, which might also be a primitive feature for neornithine birds (see above).

The cladistic analysis of Dyke \& Cooper (2000) resulted in sister group relationship between Pulchrapollia gracilis and the Psittacidae, with all other
Eocene psittaciform birds branching off more basal to this node (Fig. 8B; Dyke, 2001b: fig. 3 cited this tree but mistook the relative positions of Psittacopes and the Quercypsittidae). The authors did not list synapomorphies that support this assignment, but all characters of their data matrix which are shared by Pulchrapollia and the Psittacidae are either characteristic for zygodactyl birds in general ('tubercle on lateral border of trochlea metatarsi III', trochlea metatarsi IV retroverted), present in many other birds (trochlea metatarsi III with pronounced rims, ulna distinctly longer than humerus), or incorrect (distal end of condylus ventralis tapering to a marked point the condylus ventralis of the humerus does not taper to a point in $P$. gracilis).

\section{COMMENTS ON THE HIGHER SYSTEMATIC AFFINITIES OF THE PSITTACIFORMES}

The higher systematic affinities of the Psittaciformes are poorly resolved. Whereas some authors considered a close relationship between Psittaciformes and either Cuculiformes (e.g. Gadow, 1893) or Columbiformes (pigeons and doves) (e.g. Mayr \& Amadon, 1951; Feduccia, 1996), more recent studies resulted in sister group relationship between the Psittaciformes and a cluster of several recent taxa (e.g. Sibley \& Ahlquist, 


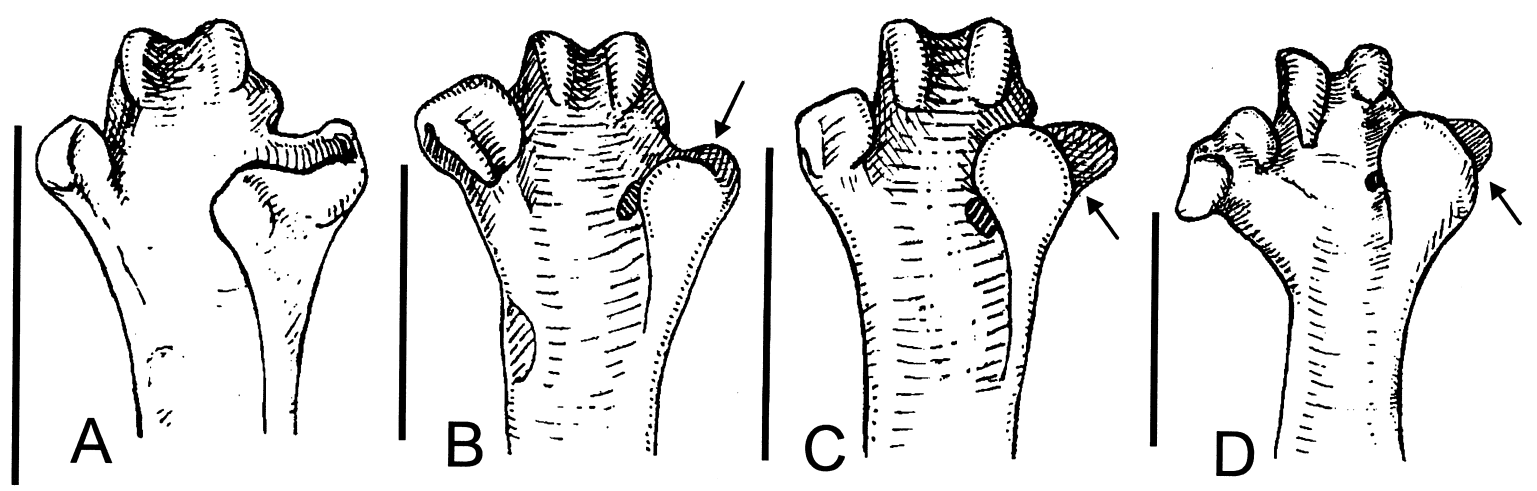

Figure 9. Distal end of left tarsometatarsus of psittaciform birds in comparison (plantar view). (A) cf. Pseudastur macrocephalus (Pseudasturidae, BMNH A 6184; Eocene) (B) Quercypsitta sudrei (Quercypsittidae; Upper Eocene), after MourerChauviré (1992); (C) cf. Psittacopes (unnamed higher-level taxon; Lower Eocene), after Mayr \& Daniels (1998: pl. 5, Fig. 16a); (D) Myiopsitta monachus (Psittacidae; recent). The arrows indicate the furrow for the tendon of musculus flexor perforatus digiti IV. Scale bars equal $5 \mathrm{~mm}$.

1990; Livezey \& Zusi, 2001 - the former reference also gives a survey on the history of the classification of psittaciform birds).

The Pseudasturidae are distinguished from other psittaciform birds in the morphology of several skeletal elements and it may be assumed that the Eocene taxon lacks many of the highly derived features, which obscure the relationships of extant Psittaciformes. Almost certainly, for example, the derived similarities between the humerus of extant parrots and pigeons (e.g. Stegmann, 1964) are due to convergence, as both the Pseudasturidae and the Eocene psittaciform birds described by Mayr \& Daniels (1998) exhibit a different, presumably more primitive, humeral morphology. Of course, the remotely parrot-like beak of the toothbilled pigeon, Didunculus strigirostris, also does not support a close relationship between Psittaciformes and Columbiformes as assumed by Feduccia (1980), because other pigeons as well as the Pseudasturidae and other basal psittaciform birds (see Mayr \& Daniels, 1998) lack a parrot-like beak.

The Pseudasturidae show some overall resemblance to strigiform birds, especially concerning the morphology of the wing skeleton. 'Primobucco' olsoni is listed as 'cuckoo/owl mosaic' in Feduccia (1996: 167) and the similarities to owls were also noted by Hoch (1988: 254), who studied a small bird from Messel which later turned out to be a member of the Pseudasturidae (see Mayr, 1998a).

Owls and parrots indeed are listed in close proximity in many of the traditional linear classifications (e.g. Mayr \& Amadon, 1951; Wetmore, 1960; Stresemann, 1927,34), but so far only few derived characters were presented, which might support a closer relationship between the two taxa (e.g. the presence of a cere at the base of the beak). Whether the similarities between Pseudasturidae and owls indi- cate a closer relationship between the latter and psittaciform birds or whether they are merely plesiomorphic resemblances needs to be examined by future anatomical studies of the extant taxa.

\section{Comments on the evolution of the Psittacidae}

The Pseudasturidae and all other Eocene psittaciform birds of which the beak is known lack the highly derived bill morphology of the Psittacidae which enables these birds to get access to their prime food resource, the substantial content of hard-shelled seeds and nuts.

The Psittacidae further differ from the Pseudasturidae and all other Eocene psittaciform birds in the highly apomorphic morphology of the tarsometatarsus, which can hardly be explained by their perching and climbing habits alone (i.e. the distal end of the bone is greatly widened, the trochlea metatarsi II unusually large, the trochlea metatarsi III bears distinctly asymmetric rims, and the trochlea accessoria is very large and distally elongated; Fig. 7B). Parrots regularly use their feet to assist husking the food (Collar, 1997: 308), and it is thus possible to regard the apomorphic tarsometatarsal morphology of the Psittacidae mainly as an adaptation to increase the grasping capabilities of the foot in order to manipulate seeds and nuts, which indeed was assumed by Steinbacher (1935: 270).

Members of the Psittacidae are also distinguished from the Pseudasturidae and the Lower Eocene psittaciform taxa described by Mayr \& Daniels (1998) in the morphology of the wing skeleton, especially the much stouter humerus. Even these differences might, however, be due to the specialized feeding technique of parrots as, according to Stegmann (1964), certain modifications in the shape of the proximal end of the 
humerus are functionally correlated to the weak and sometimes even almost completely reduced furcula of extant Psittacidae, which itself is a consequence of the large crop of these birds. Stegmann (1964) further noted that in order to get access to fruits in tree-tops, extant Psittacidae evolved the ability for hovering flight, which also resulted in modifications of the wing skeleton and the pectoral girdle.

Judging from their relative abundance in Messel and the London Clay, the Pseudasturidae probably were among the predominant small perching birds in the Eocene. So far, however, these birds have not been recorded from younger, Oligocene or Miocene deposits. On the other hand, and as already noted above, true parrots of the crown-group Psittacidae are unknown from pre-Miocene deposits. Evolution of the specialized feeding technique of the Psittacidae might have been the key event that made parrots a highly successful group with more than 300 extant species.

\section{ACKNOWLEDGEMENTS}

I thank Sandra Chapman and Angela Milner (both $\mathrm{BMNH}$ ) for the loan of the fossil specimens, S. Tränkner (Forschungsinstitut Senckenberg) for taking the photographs, and A. Manegold for technical help and comments on the manuscript. I am further indebted to C. Mourer-Chauviré and an anonymous referee for reviewing the manuscript.

\section{REFERENCES}

Baumel JJ, Witmer LM. 1993. Osteologia. In: Baumel JJ, King AS, Breazile JE, Evans HE, Vanden Berge JC, eds. Handbook of avian anatomy: Nomina Anatomica Avium. Publications of the Nuttall Ornithological Club 23: 45-132.

Björklund M. 1994. Phylogenetic relationships among Charadriiformes: reanalysis of previous data. Auk 111: 825832.

Cheneval J. 2000. L'avifaune de Sansan. In: Ginsburg L, ed. La faune miocène de Sansan et son environnement. Mémoires du Muséum National d'Histoire Naturelle 183: 321-388.

Collar NJ. 1997. Family Psittacidae (Parrots). In: del Hoyo J, Elliott A, Sargatal J, eds. Handbook of the Birds of the World, Vol. 4. Barcelona: Lynx Edicions, 280-477.

Cracraft J. 1981. Toward a phylogenetic classification of the recent birds of the world (Class Aves). Auk 98: 681-714.

Dyke GJ. 2001a. Fossil pseudasturid birds (Aves, Pseudasturidae) from the London Clay. Bulletin of the Natural History Museum of London (Geology Series) 57: 1-4.

Dyke GJ. 2001b. The evolutionary radiation of modern birds: systematics and patterns of diversification. Geological Journal 36: 305-315.

Dyke GJ, Cooper JH. 2000. A new psittaciform bird from the London Clay (Lower Eocene) of England. Palaeontology 43: 271-285.
Dyke GJ, Mayr G. 1999. Did parrots exist in the Cretaceous period? Nature 399: 317-318.

Feduccia A. 1980. The Age of Birds. Cambridge, Massachusetts: Harvard University Press.

Feduccia A. 1996. The Origin and Evolution of Birds. New Haven: Yale University Press.

Feduccia A, Martin LD. 1976. The Eocene zygodactyl birds of North America (Aves: Piciformes). Smithsonian Contributions to Paleobiology 27: 101-110.

Gadow H. 1893. Vögel. II. - Systematischer Theil. In: Bronn HG, ed. Klassen und Ordnungen des Thier-Reichs, Vol. 6 (4). Leipzig: C. F. Winter, 1-303.

Harrison CJO. 1982. The earliest parrot: a new species from the British Eocene. Ibis 124: 203-210.

Harrison CJO, Walker CA. 1977. Birds of the British Lower Eocene. Tertiary Research Special Paper 3: 1-52.

Hoch E. 1988. On the Ecological Role of an Eocene Bird from Messel, West Germany. Courier Forschungsinstitut Senckenberg 107: 249-261.

Houde P. 1988. Paleognathous birds from the early Tertiary of the Northern Hemisphere. Publications of the Nuttall Ornithological Club 22: 1-148.

Houde P, Olson S. 1989. Small Arboreal Nonpasserine Birds from the Early Tertiary of Western North America. In: Ouellet H, ed. Acta XIX Congressua Internationalia Ornithologici. Ottawa: University of Ottawa Press, 2030-2036.

Hughes JM. 2000. Monophyly and phylogeny of cuckoos (Aves, Cuculidae) inferred from osteological characters. Zoological Journal of the Linnean Society 130: 263-307.

Hughes JM, Baker AJ. 1999. Phylogenetic relationships of the enigmatic Hoatzin (Opisthocomus hoazin) resolved using mitochondrial and nuclear gene sequences. Molecular Biology and Evolution 16: 1300-1307.

Livezey BC. 1986. A phylogenetic analysis of recent anseriform genera using morphological characters. Auk 103: $737-$ 754 .

Livezey BC, Zusi RL. 2001. Higher-order phylogenetics of modern Aves based on comparative anatomy. Netherlands Journal of Zoology 51: 179-205.

Mayr G. 1998a. A new family of Eocene zygodactyl birds. Senckenbergiana Lethaea 78: 199-209.

Mayr G. 1998b. 'Coraciiforme' und 'piciforme' Kleinvögel aus dem Mittel-Eozän der Grube Messel (Hessen, Deutschland). Courier Forschungsinstitut Senckenberg 205: 1-101.

Mayr G. 2000a. Die Vögel der Grube Messel - ein Einblick in die Vogelwelt Mitteleuropas vor 49 Millionen Jahren. Natur und Museum 130: 365-378.

Mayr G. 2000b. New or previously unrecorded avian taxa from the Middle Eocene of Messel (Hessen, Germany). Mitteilungen aus dem Museum für Naturkunde in Berlin, Geowissenschaftliche Reihe 3: 207-219.

Mayr G. 2001. Comments on the systematic position of the putative Lower Eocene parrot Pulchrapollia gracilis. Senckenbergiana Lethaea 81: 339-341.

Mayr E, Amadon D. 1951. A classification of recent birds. American Museum Novitates 1360: 1-42.

Mayr G, Daniels M. 1998. Eocene parrots from Messel (Hessen, Germany) and the London Clay of Walton-on-the- 
Naze (Essex, England). Senckenbergiana Lethaea 78: 157177.

Mlíkovský J. 1996. Tertiary Avian Faunas of Europe. In: Mlíkovský J, ed. Tertiary Avian Localities of Europe. Acta Universitatia Carolinae, Geologica 39: 777-818.

Mlíkovský J. 1998. A new parrot (Aves: Psittacidae) from the early Miocene of the Czech Republic. Acta Societatia Zoologicae Bohemicae 62: 335-341.

Mourer-Chauviré C. 1992. Une nouvelle famille de Perroquets (Aves, Psittaciformes) dans l'éocène supérieur des phosphorites du Quercy, France. Geobios, Mémoire Spécial 14: 169-177.

Mourer-Chauviré C. 1996. Paleogene Avian Localities of France. In: Mlíkovský J, ed. Tertiary Avian Localities of Europe. Acta Universitatia Carolinae, Geologica 39: 567598.

Mourer-Chauviré C, Hugueney M, Jonet P. 1989. Découverte de Passeriformes dans l'Oligocène supérieur de France. Comptes Rendus de l'Académie des Sciences de Paris 309: 843-849.

Olson SL. 1985. The fossil record of birds. In: Farner DS, King JR, Parkes KC, eds. Avian Biology, Vol. 8. New York: Academic Press, 79-238.

Olson SL. 1987. Variation in the procoracoid foramen in the Accipitridae. Rivista Italiana di Ornitologia 57: 161-164.
Sibley CG, Ahlquist JE. 1990. Phylogeny and Classification of Birds: a Study in Molecular Evolution. New Haven: Yale University Press.

Stegmann B. 1963. Der Processus internus indicis im Skelett des Vogelflügels. Journal für Ornithologie 104: 413-423.

Stegmann B. 1964. Die funktionelle Bedeutung des Schlüsselbeines bei den Vögeln. Journal für Ornithologie 105: 450 463.

Steinbacher G. 1935. Funktionell-anatomische Untersuchungen an Vogelfüßen mit Wendezehen und Rückzehen. Journal für Ornithologie 83: 214-282.

Stidham T. 1998. A lower jaw from a Cretaceous parrot. Nature 396: 29-30.

Stresemann E. 1927-34. Aves. In: Kükenthal W, Krumbach, T, eds. Handbuch der Zoologie. Berlin: Walter de Gruyter.

Vanden Berge JC, Zweers GA. 1993. Myologia. In: Baumel JJ, King AS, Breazile JE, Evans HE, Vanden Berge JC, eds. Handbook of avian anatomy: Nomina Anatomica Avium. Publications of the Nuttall Ornithological Club 23: 189247.

Wetmore A. 1926. Descriptions of additional fossil birds from the Miocene of Nebraska. American Museum Novitates 211: $1-5$.

Wetmore A. 1960. A classification for the birds of the world. Smithsonian Miscellaneous Collections 139: 1-37. 